\section{Coherent calculus of subjective probability}

Theory of Probability: $A$ Critical Introductory Treatment, Vol. 2. By Bruno de Finetti. Translated by Antonio Machi and Adrian Smith. Pp. xviiit 375. (Wiley: London and New York, 1975.) $£ 10.50$.

THis is the second half of the English translation of Professor de Finetti's Italian Theory of Probability, and completes a work which, in the opinion of the foreword, "is destined ultimately to be recognised as one of the great books of the world". In reviewing the first half, besides sketching the background to the controversies which occupy the minds of many statisticians, I noted that it was the second volume which would carry Professor de Finetti's critical discussion of inductive reasoning and statistical inference, and that I awaited it with impatience (Nature, 251, 262, 1974). Now that it has arrived, it is slightly disappointing, although in other respects the author presents an invigorating and wholly dellightful account of some fascinating topics in probability theory. In treating these (chapters 7-10) he greatly strengthens his Bayesian position by his deft treatment of paradoxical examples

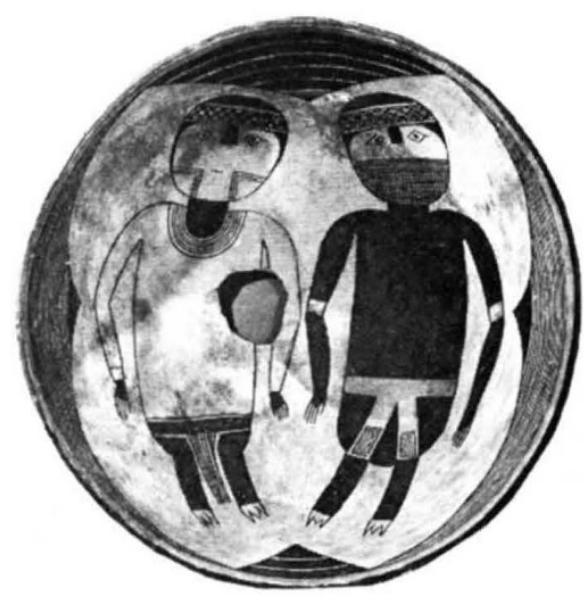

Bowl (diameter $30 \mathrm{~cm}$ ) found as part of a grave lot. New Mogollon pottery style of the 10th century AD, Mimbres area of south-western New Mexico. Decorated with a black-on-white design of enigmatic human figures, possibly representing the contrast between life and death or male and female. The hole puncturing the base, 'killing' the object, helped release the vessel's spirit into the next world. Taken from The American Indians: Their Archaeology and Prehistory. By Dean Snow. Photographs by Werner Forman. Pp. 265. (Thames and Hudson: London, April, 1976.) £6.50. (it would be too much to call these teasers of probability theory paradoxes). Studded with illuminating asides and revealing anecdotes, this part of the book is a delight. How many statisticians know that the points of inflexion of the normal distribution are at the one-standard-deviation points? Professor de Finetti knows that the tangents at these points cut the axis at the two-standard-deviation points, and such asides give the book its flavour.

Chapter 11, 'Inductive Reasoning; Statistical Inference', is the kernel of the book. "It is particularly instructive to consider the process by which new scientific theories are formulated. The first step is an intuitive one, arising out of some particular set of observations, but then various modifications are made as a result of more up-to-date results which suggest that this or that alternative theory provides a better explanation'. So far so good, but what is to be the currency of explanation? I would say likelihood, but for de Finetti: "In essence, it is always a question of analysing the current state of information by means of Bayes's theorem". Later, "In our formulation, the problem of induction is, in fact, no longer a problem: we have, in effect, solved it without mentioning it explicitly. Everything reduces to the notion of conditional probability",

The author presumes on our acquiescence, and we look in vain for arguments which will lead the doubting majority to join the congregation of the Reverend Thomas Bayes: why should scientific hypotheses be treated like statistical events? If they should be, then the Bayesian position sunely follows. for I believe de Finetti carries that part of his case-that the right calculus for events of uncertain outcome is the coherent calculus of subjective probability: it is, perhaps, his major contribution. Bayes, I think, would have approved; indeed, de Finetti could with profit have included an analyis of Bayes' paper in his book, for the one presages much that is in the other.

In fact, Bayes did not include scientific hypotheses in his scheme: that proposal is neo-Bayesian. But whatever we call it, it is the crucial issue. For me it is neither a reflection of how science does progress nor a paradigm for how it should. If universally applied it would reduce creative scientific activity to the level of accountancy. Coherence has its place, just like the double-entry book-keeping introduced by de Finetti's compatriots-the Lombard bankers of long ago: c'est magnifique, mais ce n'est pas la guerre.

But let each reader decide for himself. de Finetti's two volumes are essential reading. A. W. F. Edwards

\section{Contemporary Biology}

General Editors: E. J. W. Barrington and $A$. J. Willis

\section{Nitrogen \\ Metabolism in Plants}

Leonard Beevers

An up-to-date account of the biochemistry of nitrogen metabolism in higher plants.

Publication August

Cloth $£ 14.00$ Paper $£ 6.95$

\section{The \\ Chemotaxonomy of Plants}

\section{P. M. Smith}

A concise introduction to the applications and value of chemical evidence in taxonomic and evolutionary studies of plants and bacteria.

Publication June

Cloth $£ 13.00$ Paper $£ 6.50$

A Biologist's Guide to

\section{Principles and Techniques of Practical Biochemistry}

Brian L. Williams and Keith Wilson

Information on techniques and principles used in biochemistry for all biology students up to degree level.

Cloth $£ 7.50 \quad$ Paper $£ 3.75$

\section{The Locomotion of Soft-Bodied Animals}

\section{E. R. Trueman}

Locomotory structures and mechanisms in invertebrates are presented in the context of biomechanical studies.

Cloth $£ 8.50$ Paper $£ 4.25$

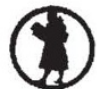

\section{Edward Arnold}

25 Hill Street, London W1X 8LL 